\title{
Iklim Kerja dan Fungsi Pengarahan Serta Pengaruhnya Terhadap Peningkatan Semangat Kerja Pegawai Kantor Kementerian Agama Oku Timur
}

\author{
Winda Feriyana \\ STIE Trisna Negara, Indonesia \\ Email corresponding author: feriyanawinda@gmail.com
}

\begin{abstract}
ABSTRAK
Sumber daya manusia perlu mendapatkanperhatian serius sehingga tujuan organisasi dapat tercapai, baik jangka panjang maupun jangka pendek.Salah satu sasaran penting dicapai oleh perusahaan dalam rangka mengembangkan sumber daya manusia adalah meningkatkan kemampuan kerja karyawan sehingga karyawan dapat menyelesaikan tugas sesuai dengan jabatan dan posisi mereka. Hal tersebut juga tidak luput dari semangat kerja seorang karyawan yang mana semangat kerja merupakan melaksanakan tugas dan pekerjaan untuk mencapai tujuan perusahaan, seorang pemimpin dibantu oleh yang lain yakni karyawan.Penelitian ini bertujuan untuk menganalisis secara parsial maupun bersama - sama pengaruh Iklim Kerja, pengarahan terhadap semangat kerja pegawai serta menganalisis variabel yang paling dominan dalam mempengaruhi semangat kerja pegawai Kantor Kementerian Agama OKU Timur, Hasil analisis regresi dan korelasi antara Iklim Kerja terhadap semangat kerja pegawai menunjukkan model regresi $\hat{Y}=3.987+0.958 X_{1}+$ e dengan koefisien korelasi sebesar 0.900. Hasil analisis regresi dan korelasi antara pengarahan terhadap semangat kerja pegawai menunjukkan model regresi $\hat{Y}=16.805+0.665 X_{2}+$ e dengan koefisien korelasi sebesar 0.825 . Hasil analisis regresi berganda dan korelasi antara iklim kerja dan pengarahan secara bersama-sama terhadap semangat kerja menunjukkan model regresi $\hat{Y}=2.817+0.675 X_{1}+$ $0.300 X_{2}+$ e dengan koefisien korelasi sebesar 0.937. Penelitian ini dilakukan kepada 28 orang responden dengan metode analisis yang digunakan adalah analisis jalur dengan menggunakan software SPSS.
\end{abstract}

Kata Kunci: Iklim kerja, pengarahan, semangat

\section{PENDAHULUAN}

Suatu organisasi akan mengalami perubahan organisasional dan perencanaan sumber daya manusia (SDM). Hal ini berarti bahwa setiap organisasi harus selalu peka terhadap kekuatan lingkungan yang mempengaruhi organisasi. Setiap perubahan selalu akan melibatkan manusia (dilakukan manusia) dan mempengaruhi terhadap pengelolaan SDM. Organisasi bisa berdiri diawali adanya beberapa tujuan tertentu yang hanya dapat dicapai melalui tindakan yang harus dilakukan dengan persetujuan bersama. Jadi apabila tujuan itu membawa kebaikan bagi anggota maupun masyarakat, Kondisi ini mewajibkan setiap daerah untuk mempunyai sumber daya manusia yang dapat diandalkan untuk melaksanakan otonomi daerah. Sumber daya manusia merupakan unsur 
terpenting, maka pemeliharaan hubungan yang kontinyu dan serasi dengan para pegawai dalam suatu perusahaan/organisasi menjadi sangat penting..

Sumber daya manusia sebagai tenaga kerja dan inti dari hidupnya sebuah organisasi harus terus berupaya untuk membenahi masing-masing dirinya sendiri yang dimulai dari menanamkan disiplin. Sikap untuk mentaati tata aturan dan pedoman yang berlaku di dalam organisasi sebaiknya dilakukan dengan senang hati tanpa paksaan.

Para pegawai yang berkiprah dalam suatu organisasi adalah sumber daya terpenting yang dapat mendayagunakan potensi sumber daya organisasi lainnya secara produktif dan pada gilirannya meningkatkan kinerja organisasi. Uraian di atas menjelaskan bahwa manajemen perlu memperhatikan faktor-faktor yang dapat memotivasi pegawai agar memiliki kinerja yang lebih baik, hal ini penting dilaksanakan agar tujuan organisasi tercapai. Apabila manajemen mampu mengungkap daya atau kekuatan yang ada dalam diri pegawai yang mendorong atau menggerakkan untuk berperilaku tertentu yang diarahkan pada tujuan, maka daya atau kekuatan itu akan mengarah pada suatu tujuan yang ingin dicapai.Kaitannya dengan hal ini, bagian Kantor Kementerian Agama OKU Timur belum secara mendalam mengkaji faktor-faktor penciptaan iklim kerja yang kondusif dan memotivasi pegawai agar berkinerja lebih baik, sehingga kondisi kerja yang ada didasarkan atas penghargaan jika memiliki motivasi tinggi dan hukuman jika motivasi kerja kurang baik. Apabila sudah terarah pada tujuan utama, maka perilaku tersebut tetap dipertahankan secara gigih agar tujuan tercapai, yaitu peningkatan kinerja pegawai seperti yang telah dikemukakan oleh Stephen P. Robbins (2003) bahwa kinerja merupakan fungsi dari kemampuan, motivasi dan kesempatan, dan oleh Rivai (2005) faktor kesempatan itu disebut faktor lingkungan atau iklim kerja.

Iklim kerja merupakan suatu kondisi atau keadaan suasana kerja yang berada di instansi dirasa nyaman, tenang, dan bebas dalam melakukan pekerjaan tanpa adanya rasa takut. Iklim kerja yang menyenangkan akan tercipta, apabila hubungan antar manusia berkembang dengan harmonis. Keadaan iklim yang harmonis ini sangat mendukung terhadap prestasi kerja pegawai. Dengan adanya suasana kerja yang nyaman dan tenang tersebut memungkinkan pegawai untuk bekerja lebih baik. Kegiatan dan perilaku antara karyawan dengan pimpinan, sangat menentukan iklim di suatu lingkungan kerja. Dengan demikian, perusahaan harus dapat menentukan tujuan organisasinya untuk menciptakan iklim yang tepat sesuai dengan tujuan para karyawannya. Karena persepsi terhadap baik buruknya iklim kerja ditentukan oleh penilaian karyawan itu sendiri. 


\section{KAJIAN TEORI}

\section{Pengertian Iklim Kerja}

Iklim kerja atau kondisi lingkungan kerja pada suatu kantor sangat berpengaruh pada para karyawan atau para pegawai. Suatu iklim kerja yang baik/bagus dapat meningkatkan kinerja para pegawainya. Tetapi jika lingkungan kerja kurang bagus atau tidak memadai dapat menurunkan kinerja dan menurunkan motivasi kerja karyawan.

Lingkungan kerja atau iklim tersebut dikatakan baik dan sesuai jika para karyawannya dapat melaksanakan kegiatan secara optimal, sehat, aman, dan nyaman. Dalam jangka waktu yang lama kesesuaian lingkungan kerja tersebut dapat terlihat. Tetapi jika lingkungan kerja yang kurang baik akan menuntut tenaga kerja dan waktu yang lebih banyak, sehingga tidak mendukung diperolehnya rancangan sistem kerja yang efisien.

Selain iklim kerja yang diperhatikan dalam suatu kantor, motivasi kerja pegawai kantor juga perlu diperhatikan. Karena motivasi kerja dapat mendorong seseorang menjadi semangat bekerja. Dan kuat lemahnya motivasi kerja seseorang berpengaruh dengan besar kecilnya prestasi yang didapatkan. Motivasi biasanya diberikan kepada bawahan atau pengikut.

Menurut Alex S Nitisemito (2000:183) mendefinisikan lingkungan kerja sebagai berikut: "Lingkungan kerja adalah segala sesuatu yang ada disekitar para pekerja yang dapat mempengaruhi dirinya dalam menjalankan tugas-tugas yang diembankan".

Menurut Sedarmayati (2001:1) mendefinisikan lingkungan kerja sebagai berikut :"Lingkungan kerja adalah keseluruhan alat perkakas dan bahan yang dihadapi, lingkungan sekitarnya di mana seseorang bekerja, metode kerjanya, serta pengaturan kerjanya baik sebagai perseorangan maupun sebagai kelompok".

Sehingga dapat disimpulkan bahwa lingkungan kerja merupakan "segala sesuatu yang ada di sekitar karyawan pada saat bekerja, baik yang berbentuk fisik ataupun non fisik, langsung atau tidak langsung, yang dapat mempengaruhi dirinya dan pekerjaanya saat bekerja".

Menurut Sedarmayanti (2001:21) jenis lingkungan kerja terbagi menjadi dua, yakni:

1. Lingkungan kerja Fisik

Menurut Sedarmayanti (2001:21), “Lingkungan kerja fisik adalah semua keadaan berbentuk fisik yang terdapat di sekitar tempat kerja yang dapat mempengaruhi karyawan baik secara langsung maupun scara tidak langsung. Lingkungan kerja fisik dapat dibagi dalam dua kategori, yaitu :

1) Lingkungan yang langsung berhubungan dengan karyawan (Seperti: pusat kerja, kursi, meja dan sebagainya).

2) Lingkungan perantara atau lingkungan umum dapat juga disebut lingkungan kerja yang mempengaruhi kondisi manusia, misalnya:temperatur, 
kelembaban, sirkulasi udara, pencahayaan, kebisingan, getaran mekanis, bau tidak sedap, warna, dan lain-lain.

Untuk dapat memperkecil pengaruh lingkungan fisik terhadap karyawan, maka langkah pertama adalah harus mempelajari manusia, baik mengenai fisik dan tingkah lakunya maupun mengenai fisiknya, kemudian digunakan sebagai dasar memikirkan lingkungan fisik yang sesuai.

2. Lingkungan Kerja Non Fisik

Menurut Sadarmayanti (2001:31), “Lingkungan kerja non fisik adalah semua keadaan yang terjadi yang berkaitan dengan hubungan kerja, baik hubungan dengan atasan maupun hubungan sesama rekan kerja, ataupun hubungan dengan bawahan".Lingkungan non fisik ini juga merupakan kelompok lingkungan kerja yang tidak bisa diabaikan.

Menurut Alex Nitisemito (2000:171-173) Perusahaan hendaknya dapat mencerminkan kondisi yang mendukung kerja sama antara tingkat atasan, bawahan maupun yang memiliki status jabatan yang sama di perusahaan. Kondisi yang hendaknya diciptakan adalah suasana kekeluargaan, komunikasi yang baik, dan pengendalian diri.

Suryadi Perwiro Sentoso (2001:19-21) yang mengutip pernyataan Prof. Myon Woo Lee sang pencetus teori W dalam Ilmu Manajemen Sumber Daya Manusia, bahwa pihak manajemen perusahaan hendaknya membangun suatu iklim dan suasana kerja yang bisa membangkitkan rasa kekeluargaan untuk mencapai tujuan bersama.

Pihak manajemen perusahaan juga hendaknya mampu mendorong inisiatif dan kreativitas. Kondisi seperti inilah yang selanjutnya menciptakan antusiasme untuk bersatu dalam organisasi perusahaan untuk mencapai tujuan.

\section{METODE PENELITIAN}

Data yang digunakan adalah data primer berupa hasil kuesioner yang disebarkan kepada pegawai Kantor Kementerian Agama OKU Timur. Variabel yang diteliti oleh peneliti ada dua yaitu variabel pertama adalah variabel bebas yang terdiri dari variabel iklim kerja dan pengarahan, sedangkan variabel yang kedua adalah variabel terikat yaitu variabel semangat kerja pegawai dengan melakukan tekhnik analisis data sebagai berikut :

\section{Tekhnik Analisis Data}

\section{Skala Likert}

R. S Likert mengembangkan prosedur penskalaan dimana skala mewakili suatu countinum bipolar, pada ujung sebelah kiri dengan angka rendah menggambarkan jawaban yang negative, sedangkan ujung sebelah kanan dengan angka besar / tinggi yang menggambarkan jawaban yang positif. Format likert dirancang untuk 
memungkinkan pelanggan menjawab dalam berbagai tingkatan pada setiap butir yang menguraikan variabel - variabel yang diteliti. Format Check List yang memberikan jawaban ( Ya ) atau ( Tidak ) dengan kisaran skala antara 1 sampai dengan 5
1. Sangat Setuju (SS)
: Skor 5
2. Setuju (S)
: Skor 4
3. Kurang Setuju (KS)
: Skor 3
4. Tidak Setuju (TS)
: Skor 2
5. Sangat Tidak Setuju (STS)
: Skor 1

\section{Analisis Validitas}

Validitas menunjukkan tingkat yang digunakan sebagai bukti pendukung kesimpulan yang ditarik dari nilai yang diturunkan dari tingkat dimana skala mengukur sesuatu yang harus diukur. Suatu data dikatakan valid apabila nilai corrected item lebih besar dari nilai $r$ tabel dengan $\mathrm{df}=\mathrm{n}-2$ atau Validitas instrument ketiga variabel dinilai dengan cara menghitung data dengan rumus Pearson Product Moment dalam program Komputer SPSS. Butir pernyataan/pertanyaan dinyatakan valid jika nilai Pearson Product Moment> $\mathrm{r}$ Tabel yang ditandai dengan $\left(^{*}\right)$ dan $\left(^{* *}\right)$. Angka kritis korelasi tabel (Tabel r) adalah 0,361. Angka ini diperoleh dari tabel r-product moment pada taraf signifikansi 5\% $(\alpha=0,05)$ dan $\mathrm{N}=28$ (sesuai jumlah responden). Dengan demikian apabila ada koefisien korelasi butir pertanyaan / pernyataan berada dibawah 0,361 maka dinyatakan tidak valid.

\section{TEMUAN DAN PEMBAHASAN}

\section{Instrument Iklim Kerja $\left(X_{1}\right)$}

Tabel 1. Hasil Uji Validitas Instrument Variabel Iklim Kerja

\begin{tabular}{|c|c|c|c|c|}
\hline Pertanyaan & $\begin{array}{c}\text { Pearson } \\
\text { Correlation ( } \mathrm{r} \\
\text { hitung) } \\
\end{array}$ & $\mathbf{r}$ tabel & Variabel Iklim $\left(X_{1}\right)$ & Keterangan \\
\hline Pertanyaan 1 & $.399^{*}$ & 0.361 & $\mathrm{r}$ hitung $>\mathrm{r}$ tabel & Valid \\
\hline Pertanyaan 2 & .129 & 0.361 & $\mathrm{r}$ hitung $<\mathrm{r}$ tabel & Tidak Valid \\
\hline Pertanyaan 3 & $.498^{* *}$ & 0.361 & $\mathrm{r}$ hitung $>\mathrm{r}$ tabel & Valid \\
\hline Pertanyaan 4 & $.693^{* *}$ & 0.361 & $r$ hitung $>r$ tabel & Valid \\
\hline Pertanyaan 5 & $.445^{*}$ & 0.361 & $\mathrm{r}$ hitung $>\mathrm{r}$ tabel & Valid \\
\hline Pertanyaan 6 & $.429^{*}$ & 0.361 & $\mathrm{r}$ hitung $>\mathrm{r}$ tabel & Valid \\
\hline Pertanyaan 7 & $.438^{*}$ & 0.361 & $r$ hitung $>r$ tabel & Valid \\
\hline Pertanyaan 8 & $.692^{* *}$ & 0.361 & $\mathrm{r}$ hitung $>\mathrm{r}$ tabel & Valid \\
\hline Pertanyaan 9 & .085 & 0.361 & $\mathrm{r}$ hitung $<\mathrm{r}$ tabel & Tidak Valid \\
\hline Pertanyaan 10 & $.656^{* *}$ & 0.361 & $\mathrm{r}$ hitung $>\mathrm{r}$ tabel & Valid \\
\hline Pertanyaan 11 & $.406^{*}$ & 0.361 & $\mathrm{r}$ hitung $>\mathrm{r}$ tabel & Valid \\
\hline Pertanyaan 12 & .066 & 0.361 & $\mathrm{r}$ hitung $<\mathrm{r}$ tabel & Tidak Valid \\
\hline
\end{tabular}


Instrument Pengarahan $\left(X_{2}\right)$

Tabel 1. Hasil Uji Validitas Instrument Variabel Pengarahan $\left(\mathrm{X}_{2}\right)$

\begin{tabular}{ccccc}
\hline Pertanyaan & $\begin{array}{c}\text { Pearson Correlation } \mathbf{( r} \\
\text { hitung) }\end{array}$ & $\mathbf{r}$ tabel & $\begin{array}{c}\text { Variabel } \\
\left.\text { Pengarahan } \mathbf{X}_{\mathbf{2}}\right)\end{array}$ & Keterangan \\
\hline Pertanyaan 1 & $.382^{*}$ & 0.361 & $\mathrm{r}$ hitung $>\mathrm{r}$ tabel & Valid \\
Pertanyaan 2 & $.776^{* *}$ & 0.361 & $\mathrm{r}$ hitung $>\mathrm{r}$ tabel & Valid \\
Pertanyaan 3 & .248 & 0.361 & $\mathrm{r}$ hitung $<\mathrm{r}$ tabel & Tidak Valid \\
Pertanyaan 4 & $.382^{*}$ & 0.361 & $\mathrm{r}$ hitung $>\mathrm{r}$ tabel & Valid \\
Pertanyaan 5 & $.776^{* *}$ & 0.361 & $\mathrm{r}$ hitung $>\mathrm{r}$ tabel & Valid \\
Pertanyaan 6 & .160 & 0.361 & $\mathrm{r}$ hitung $<\mathrm{r}$ tabel & Tidak Valid \\
Pertanyaan 7 & .216 & 0.361 & $\mathrm{r}$ hitung $<\mathrm{r}$ tabel & Tidak Valid \\
Pertanyaan 8 & $.382^{*}$ & 0.361 & $\mathrm{r}$ hitung $>\mathrm{r}$ tabel & Valid \\
Pertanyaan 9 & $.776^{* *}$ & 0.361 & $\mathrm{r}$ hitung $>\mathrm{r}$ tabel & Valid \\
Pertanyaan 10 & .248 & 0.361 & $\mathrm{r}$ hitung $<\mathrm{r}$ tabel & Tidak Valid \\
Pertanyaan 11 & .329 & 0.361 & $\mathrm{r}$ hitung $<\mathrm{r}$ tabel & Tidak Valid \\
Pertanyaan 12 & $.561^{* *}$ & 0.361 & $\mathrm{r}$ hitung $>\mathrm{r}$ tabel & Valid \\
\hline
\end{tabular}

\section{Instrument Semangat Kerja Pegawai (Y)}

Tabel 1. Hasil Uji Validitas Instrumen Variabel Semangat Kerja Pegawai (Y)

\begin{tabular}{lcccc}
\hline Pertanyaan & $\begin{array}{c}\text { Pearson } \\
\text { Correlation }(\mathbf{r} \\
\text { hitung) }\end{array}$ & $\mathbf{r}$ tabel & $\begin{array}{c}\text { Variabel Semangat } \\
\text { Kerja }(\mathbf{Y})\end{array}$ & Keterangan \\
\hline Pertanyaan 1 & .253 & 0.361 & $\mathrm{r}$ hitung $<\mathrm{r}$ tabel & Tidak Valid \\
Pertanyaan 2 & $.645^{* *}$ & 0.361 & $\mathrm{r}$ hitung $>\mathrm{r}$ tabel & Valid \\
Pertanyaan 3 & $.645^{* *}$ & 0.361 & $\mathrm{r}$ hitung $>\mathrm{r}$ tabel & Valid \\
Pertanyaan 4 & $.724^{* *}$ & 0.361 & $\mathrm{r}$ hitung $>\mathrm{r}$ tabel & Valid \\
Pertanyaan 5 & .331 & 0.361 & $\mathrm{r}$ hitung $<\mathrm{r}$ tabel & Tidak Valid \\
Pertanyaan 6 & $.386^{*}$ & 0.361 & $\mathrm{r}$ hitung $>\mathrm{r}$ tabel & Valid \\
Pertanyaan 7 & .337 & 0.361 & $\mathrm{r}$ hitung $<\mathrm{r}$ tabel & Tidak Valid \\
Pertanyaan 8 & $.502^{* *}$ & 0.361 & $\mathrm{r}$ hitung $>\mathrm{r}$ tabel & Tidak Valid \\
Pertanyaan 9 & .253 & 0.361 & $\mathrm{r}$ hitung $<\mathrm{r}$ tabel & Valid \\
Pertanyaan 10 & $.645^{* *}$ & 0.361 & $\mathrm{r}$ hitung $>\mathrm{r}$ tabel & Valid \\
Pertanyaan 11 & $.645^{* *}$ & 0.361 & $\mathrm{r}$ hitung $>\mathrm{r}$ tabel & Valid \\
Pertanyaan 12 & $.724^{* *}$ & 0.361 & $\mathrm{r}$ hitung $>\mathrm{r}$ tabel & \\
\hline
\end{tabular}

\section{Analisis Reliabilitas}

Reliabilitas adalah reliabilitas adalah suatu nilai yang menunjukkan konsistensi suatu alat pengukur dalam mengukur gejala yang sama.Reliabilitas digunakan sebagai seberapa jauh pengukuran bebas dari varian kesalahan dalam memperkirakan kehandalan dari variabel yang diteliti, peneliti menggunakan metode Cronbach Alphadengan menggunakan alat bantu program komputer SPSS. Suatu instrument variabel dikatakan handal jika nilai Cronbach's Alpha > 0,6. uji reliabilitas Iklim kerja didapat nilai Cronbach Alpha sebesar 0.689, uji reliabilitas 
pengarahan didapat nilai Cronbach Alpha sebesar 0.772 sedangkan semangat kerja setelah dilakukan uji reliabilitas didapat nilai Cronbach Alpha sebesar 0.712 .

\section{Instrumen Variabel Iklim Kerja $\left(X_{1}\right)$}

Dari uji coba yang dilakukan untuk instrument Iklim Kerja $\left(\mathrm{X}_{1}\right)$ dari 12 butir pertanyaan yang dilakukan uji reliabilitas didapat nilai Cronbach Alpha sebesar 0.689, nilai alpha ini termasuk baik karena berada pada nilai 0,6 pada nilai Cronbach Alpha, dan dapat disimpulkan bahwa instrumen variabel iklim kerja $\left(\mathrm{X}_{1}\right)$ dapat dikatakan reliabel.

Reliability Statistics

Cronbach's Alpha N of Items .689 9

Instrumen Variabel Pengarahan $\left(\mathrm{X}_{2}\right)$

Dari uji coba yang dilakukan untuk instrument Pengarahan $\left(X_{2}\right)$ dari 12 butir pertanyaan yang dilakukan uji reliabilitas didapat nilai Cronbach Alpha sebesar 0.772, nilai alpha ini termasuk sangat baik karena berada diatas nilai 0,6 pada nilai Cronbach Alpha, dan dapat disimpulkan bahwa instrumen variabel Pengarahan $\left(\mathrm{X}_{2}\right)$ dapat dikatakan reliabel.

Reliability Statistics

Cronbach's Alpha N of Items

.772

7

Instrumen variabel Semangat Kerja Pegawai $(Y)$

Dari uji coba yang dilakukan untuk instrument semangat Kerja pegawai $(\mathrm{Y})$ dari 12 butir pertanyaan yang dilakukan uji reliabilitas didapat nilai Cronbach Alpha sebesar 0.712, nilai alpha ini termasuk sangat baik karena berada diatas nilai 0,6 pada nilai Cronbach Alpha, dan dapat disimpulkan bahwa instrumen variabel semangat kerja pegawai (Y) dapat dikatakan reliabel.

Reliability Statistics

Cronbach's Alpha N of Items

$.712 \quad 8$

\section{Analisis Korelasi dan Regresi}

Menggunakan pengujian assoiatif yang bertujuan mengetahui hubungan dua variabel, analisis regresi serta untuk mencari persamaan. Untuk mengukur pengaruh hubungan antar variabel digunakan besaran yang akan dianalisis adalah korelasi ( $\mathrm{r}$ ).Nilai koefisien berkisar antara -1 dan 1, semakin mendekati satu nilai 
absolute koefisien korelasi maka pengaruh antara variabel tersebut semakin kuat sedangkan semakin kecil (mendekati nol) nilai absolute koefisien korelasi maka pengaruh antara variabel tersebut semakin lemah. Sedangkan pengujian regresi digunakan untuk melihat pengaruh variabel - variabel yang diteliti menggunakan regresi linier berganda dan regresi linier sederhana.

\section{Analisis Regresi Linier}

Uji Linearitas Pengaruh Iklim Kerja $\left(X_{1}\right)$ terhadap Semangat kerja (Y)

Berdasarkan hasil uji perhitungan uji linearitas dengan program SPSS untuk variabel Iklim Kerja $\left(\mathrm{X}_{1}\right)$ terhadap semangat kerja pegawai $(\mathrm{Y})$ diperoleh nilai sig deviationfrom linearity sebesar $0.304<0.05$ maka dapat disimpulkan bahwa pengaruh antara Iklim kerja $\left(\mathrm{X}_{1}\right)$ terhadap semangat kerja pegawai $(\mathrm{Y})$ Linear.

ANOVA Table

\begin{tabular}{|c|c|c|c|c|c|c|}
\hline & & & Sum of Squares $\mathrm{df}$ & $\begin{array}{l}\text { Mean } \\
\text { Square }\end{array}$ & $\mathbf{F}$ & Sig. \\
\hline \multirow{5}{*}{$\begin{array}{l}\text { semangat kerja * } \\
\text { Pengorganisasian }\end{array}$} & \multirow{3}{*}{$\begin{array}{l}\text { Between } \\
\text { Groups }\end{array}$} & (Combined) & 285.25010 & 28.525 & 20.418 & .000 \\
\hline & & Linearity & $250.517 \quad 1$ & 250.517 & 179.318 & .000 \\
\hline & & $\begin{array}{l}\text { Deviation from } \\
\text { Linearity }\end{array}$ & 34.7339 & 3.859 & 2.762 & .034 \\
\hline & \multicolumn{2}{|c|}{ Within Groups } & 23.75017 & 1.397 & & \\
\hline & \multicolumn{2}{|l|}{ Total } & 309.00027 & & & \\
\hline
\end{tabular}

Uji Linearitas Pengaruh Pengarahan $\left(X_{2}\right)$ dan Semangat Kerja $(Y)$

Berdasarkan hasil perhitungan uji linearitas untuk variabel Pengarahan $\left(\mathrm{X}_{2}\right)$ terhadap semangat Kerja pegawai (Y) diperoleh nilai sig deviationfrom linearity sebesar $0.371>0.05$ maka dapat disimpulkan bahwa pengaruh antara Pengarahan $\left(\mathrm{X}_{2}\right)$ terhadap semangat kerja pegawai $(\mathrm{Y})$ Linear.

ANOVA Table

\begin{tabular}{|c|c|c|c|c|c|c|c|}
\hline & & & Sum of Squares & df & $\begin{array}{l}\text { Mean } \\
\text { Square }\end{array}$ & $\mathbf{F}$ & Sig. \\
\hline \multirow{6}{*}{$\begin{array}{l}\text { semangat kerja * } \\
\text { Pengarahan }\end{array}$} & \multirow{4}{*}{$\begin{array}{l}\text { Between } \\
\text { Groups }\end{array}$} & (Combined) & 264.283 & 14 & 18.877 & 5.488 & .002 \\
\hline & & & & & & & \\
\hline & & Linearity & 210.399 & 1 & 210.399 & 61.167 & .000 \\
\hline & & $\begin{array}{l}\text { Deviation from } \\
\text { Linearity }\end{array}$ & 53.885 & 13 & 4.145 & 1.205 & .371 \\
\hline & \multicolumn{2}{|c|}{ Within Groups } & 44.717 & 13 & 3.440 & & \\
\hline & \multicolumn{2}{|l|}{ Total } & 309.000 & 27 & & & \\
\hline
\end{tabular}




\section{Analisis Inferensial}

Analisis Regresi Berganda

Untuk menetapkan persamaan regresi berganda pengaruh iklim kerja $\left(\mathrm{X}_{1}\right)$ dan Pengarahan $\left(\mathrm{X}_{2}\right)$ secara bersama-sama terhadap semangat kerja pegawai $(\mathrm{Y})$ perlu dilakukan analisis koefisien regresi ganda, dengan menggunakan fasilitas program SPSS, maka hasilnya dapat dilihat pada tabel berikut :

Koefisien regresi Dan Uji Signifikansi

Pengaruh iklim kerja Dan Pengarahan Terhadap semangat kerja

\begin{tabular}{|c|c|c|c|c|c|c|}
\hline \multicolumn{7}{|c|}{ Coefficients ${ }^{a}$} \\
\hline \multirow[t]{2}{*}{ Model } & \multicolumn{2}{|c|}{ Unstandardized Coefficients } & \multirow{2}{*}{$\begin{array}{c}\begin{array}{c}\text { Standardized } \\
\text { Coefficients }\end{array} \\
\text { Beta }\end{array}$} & & \multirow[t]{2}{*}{$\mathbf{t}$} & \multirow[t]{2}{*}{ Sig. } \\
\hline & B & Std. Error & & & & \\
\hline 1 (Constant) & 2.817 & 3.464 & & & .813 & .424 \\
\hline iklim kerja & .675 & .106 & & .635 & 6.389 & .000 \\
\hline Pengarahan & .300 & .080 & & .372 & 3.747 & .001 \\
\hline a. Dependent V & semangat kerja & & & & & \\
\hline
\end{tabular}

Sumber : Diolah peneliti dengan program SPSS

Berdasarkan hasil analisis koefisien regresi ganda pada tabel tersebut maka persamaan regresi linear ganda pengaruh antara Iklim kerja $\left(X_{1}\right)$, Pengarahan $\left(X_{2}\right)$ dan semangat kerjaPegawai $(\mathrm{Y})$ adalah :

$$
\hat{\mathrm{Y}}=2.675+0.675 \mathrm{X}_{1}+0.300 \mathrm{X}_{2}+\mathrm{e}
$$

Dari persamaan diatas dapat dijelaskan bahwa konstanta regresi adalah 2.675 artinya jika mengabaikan variabel iklim kerja dan pengarahan maka skor semangat kerja pegawai 2.675. koefisien regresi iklim $\operatorname{kerja}\left(\mathrm{X}_{1}\right)$ adalah 0.675 artinya setiap penambahan satu satuan skor iklim kerja $\left(X_{1}\right)$ akan meningkatkan skor semangat kerja pegawai sebesar 0.675 dengan menjaga skor pengarahan $\left(X_{2}\right)$ adalah 0.300 artinya setiap penambahan satu satuan skor pengarahan akan meningkatkan skor semangat kerja pegawai sebesar 0.300 dengan menjaga skor pengarahan $\left(\mathrm{X}_{2}\right)$ tetap / konstan.

Dari persamaan regresi linear ganda diatas memperlihatkan kalau variabel iklim kerja $\left(X_{1}\right)$ lebih dominan pengaruhnya terhadap semangat kerja pegawai dibandingkan pengarahan. Sehingga untuk meningkatkan semangat kerja pegawai pada Kantor Kementerian Agama OKU Timur secara optimal, maka yang harus lebih dahulu diperhatikan untuk diperbaiki dan ditingkatkan adalah masalah iklim kerja didalam organisasi.

\section{Analisis Korelasi Determinasi}

Analisis korelasi Determinasi adalah untuk melihat besarnya variabel pengorganisasian dan pengarahan secara bersama-sama terhadap semangat kerja 
pegawai. Hasil analisis koefisien korelasi $(R)$ variabel iklim kerja $\left(X_{1}\right)$ dan Pengarahan $\left(\mathrm{X}_{2}\right)$ secara bersama-sama terhadap semangat kerja pegawai $(\mathrm{Y})$ adalah sebesar 0.937 artinya pengaruh antara iklim kerja dan pengarahan secara bersamasama terhadap semangat kerja pegawai menunjukkan adanya korelasi yang sangat kuat dan bersifat positif (searah). Sedangkan nilai koefisien determinasi (Adjusted Rsquare) iklim kerja $\left(X_{1}\right)$ dan pengarahan $\left(X_{2}\right)$ secara bersama-sama terhadap semangat kerja pegawai (Y) adalah 0.869 artinya variasi skor variabel semangat kerjapegawai dapat dijelaskan atau berpengaruh terhadap variabel iklim kerja $\left(\mathrm{X}_{1}\right)$ dan pengarahan $\left(\mathrm{X}_{2}\right)$ secara bersama-sama sebesar $86.9 \%$ dalam model regresi ganda yang dihasilkan, sedangkan sisanya menunjukkan bahwa skor semangat kerja pegawai mempunyai pengaruh terhadap variabel lain yang tidak diteliti, hasil analisis selengkapnya ditampilkan pada tabel berikut ini :

Koefisien Korelasi Dan Determinasi

Pengaruh Iklim Kerja Dan Pengarahan Terhadap Semangat Kerja

\begin{tabular}{llrrrr}
\hline \multicolumn{5}{c}{ Model Summary } \\
\hline Model & R & R Square & \multicolumn{1}{c}{ Adjusted R Square } & \multicolumn{2}{c}{ Std. Error of the Estimate } \\
\hline 1 & $.937^{\mathrm{a}}$ & .879 & .869 & 1.224 \\
\hline
\end{tabular}

\section{KESIMPULAN DAN SARAN}

Dari hasil dan pembahasan maka dapat ditarik kesimpulan sebagai berikut:

1. Secara bersama - sama iklim kerja $\left(X_{1}\right)$ dan Pengarahan $\left(X_{2}\right)$ terhadap semangat kerja pegawai pada Kantor Kementerian Agama OKU Timur, namun iklim kerjapengaruhnya lebih dominan dibandingkan dengan pengarahan yaitu $\hat{Y}=$ $2.817+0.675 X_{1}+0.300 X_{2}+$ e dengan koefisien korelasi sebesar 0.937 pada taraf kepercayaan 95\% diperoleh pengertian bahwa iklim kerja dan pengarahan secara simultan dapat memprediksi semangat kerjapegawai.

2. Uji seluruh variabel yang diteliti dinyatakan valid dan reliable yaitu uji reliabilitas iklim kerjadidapat nilai Cronbach Alpha sebesar 0.689, uji reliabilitas pengarahan didapat nilai Cronbach Alpha sebesar 0.772 dan uji reliabilitas semangat kerjadidapat nilai Cronbach Alpha sebesar 0.712 dengan standar nilai realibilitas Cronbach Alpha $\geq 0,6$

Dari hasil dan pembahasan maka disarankan:

1. Bagi pegawai Kantor Kementerian Agama OKU Timur, agar dapat meningkatkan semangat kerjanya secara optimal, melaksanakan tugas sesuai persyaratan tekhnis serta mampu meningkatkan kedisiplinan dalam dirinya.

2. Selain itu yang harus dilakukan pimpinan organisasi adalah memberikan kesempatan untuk promosi kepada pegawai yang memiliki tingkat kinerja yang tinggi atau berprestasi hendaknya diberikan penghargaan, plakat, atau bentukbentuk lain yang bukan benda akan tetapi dipandang mempunyai nilai yang 
tinggi bagi penerima sehingga dapat meningkatkan statusnya dimata orang lain baik di dalam maupun di luar organisasi.

\section{DAFTAR PUSTAKA}

Alex. S. Nitisemito, 2002, Manajemen Personalia. Edisi Revisi, Penerbit Ghalia Indonesia.

Arikunto, Suharsimi. 2006. Prosedur Penelitian Suatu Pendekatan Praktik. Jakarta: Rineka Cipta.

Benny Usman. Pengaruh Iklim Kerja Dan Semangat Kerja Terhadap Kinerja Pegawai Universitas Pgri Palembang. Jurnal Media Wahana Ekonomika, Vol. 8, No.2,Juli 2011 : $98-116$.

Handoko, Hani T, 1985. Manajemen, BPFE, Yogyakarta.

Hasibuan, Malayu. 2004. Manajemen Sumber Daya Manusia. Bina Aksara. Jakarta Dressler, G. (2009), Manajemen Sumber Daya Manusia, Penerbit Index, Jakarta.

Hasibuan, Malayu. 2004. Manajemen Sumber Daya Manusia. Bina Aksara. Jakarta Dressler, G. (2009), Manajemen Sumber Daya Manusia, Penerbit Index, Jakarta. Hidayat, Syarifudin dan Sedarmayanti. (2002). Metode Penelitian Administrasi. Alfabeta: Bandung

Ishak Syahropi. Pengaruh Semangat Kerja Terhadap Kinerja Karyawan Pt. Bangkinang Di Pekanbaru. JOM FISIP Volume 3 No. 2 Oktober 2016.

Mangkunegara, A.A. Anwar P. (2004), Manajemen Sumber Daya ManusiaPerusahaan, Remaja Rosdakarya, Bandung.

Nitisemito, Alex S. 2002. Manajemen Personalia. Cetakan Kesembilan, Edisi Ketiga. Jakarta: Ghali Indonesia.

Robbines, Steven P. 2003. Perilaku Organisasi, Edisi Bahasa Indonesia Jilid 2. PT Indek Kelompok Gramedia, Jakarta.

Stoner, James AF., R. Edward Freeman, Daniel R G R. Gilbert Jr., Manajemen, 1996. Diterjemahkan Sindiro. PT. Prenhalido, Jakarta.

Sugiyono. (2002). Metode Penel itian Bisnis. Alfabeta: Bandung

Sumantri. (2004). Perilaku Organisasi. Universitas Padjadjaran: Bandung

Umar Husein, 2000. Riset Sumber Daya Manusia. Jakarta; PT. Gramedia Pustaka Utama, Jakarta.

Veithzal, Rivai. (2005). Manajemen Sumber Daya Manusia. Raja Grafindo Persada: Jakarta.

Yoeyong Rahsel. Kinerja Pegawai Universitas Padjadjaran Bandung: Iklim Kerja Dan Motivasi KerjaJurnal Manajemen Magister, Vol. 03. No.01, Januari 2017. 